\title{
POLITIK KOLONIAL DAN PERKEMBANGAN SENI TARI DI PURO PAKUALAMAN PADA MASA PEMERINTAHAN PAKU ALAM IV \\ (1864-1878)
}

\section{Oleh : HY. Agus Murdiyastomo}

ABSTRAK

Pusat budaya di Yogyakarta selama ini yang lebih banyak diketahui oleh masyarakat adalah Kraton Kasultanan Yogyakarta, tetapi sesungguhnya selain Kraton Kasutanan masih terdapat pusat budaya yang lain yaitu Pura Paku Alaman. Di Kadipaten telah terlahir tokoh-tokoh yang sangat memperhatikan kelestarian budaya Jawa khususnya seni tari tradisi. Salah satunya adalah Kanjeng Gusti Pangeran Adipati Aryo Paku Alam IV, yang pada masa ia berkuasa, budaya Barat yang dibawa oleh kaum kolonialis melanda daerah jajahan. Hadirnya budaya asing tentu sulit untuk ditolak. Namun demikian denga piawainya KGPAA Paku Alam IV, justru mengadopsi budaya Barat, tetapi ditampilkan dengan rasa dan estetika Jawa, dalam bentuk tari klasik. Sehingga pada masanya lahir repertoar tari baru yang memperkaya seni tari tradisi. Penelitian ini bertujuan untuk mengungkap perkembangan seni tari di Pura Pakualaman pada masa pemerintahan KGPAA Paku Alam IV, dan hal-hal apa yang melatarbelakangi penciptaannya.

Dalam rangka mewujudkan rekonstruksi ini dilakukan dengan metode sejarah kritis, yang tahapannya meliputi Pertama, Heuristik, atau pencarian dan pengumpulan sumber data sejarah, yang dalam hal ini dilakukan di BPAD DIY, dan di Perpustakaan Pura Pakualaman. Di kedua lembaga tersebut tersimpan arsip tentang Paku Alaman, dan juga naskahnaskah yang berkaitan dengan penciptaan tari. Kedua, Kritik, atau pengujian terhadap sumber-sumber yang terkumpul, sumber yang telah terkumpul diuji dari segi fisik untuk memperoleh otentisitas, kemudian membandingkan informasi yang termuat dengan informasi dari sumber yang berbeda, untuk memperoleh keterpercayaan atau kredibilitas. Ketiga, Interpretasi yaitu informasi yang ada dikaji untuk diangkat fakta-fakta sejarahnya, yang kemudian dirangkai menjadi sebuah kisah sejarah. Untuk memperkuat interpratasi dan pemaknaan rangkaian fakta digunakan juga pendekatan budaya dalam hal ini digunakan teori akulturasi dan asimilasi. Keempat Kisah yang terangkai kemudian dituangkan dalam tulisan laporan dengan mengikuti kaidah dan teknik penulisan sejarah.

Hasil penelitian menunjukan, bahwa paska serangan Inggris ke Kasultanan Yogyakarta, aktivitas social politik dan ekonomi tidak dapat dilakukan dengan leluasa. Sehubungan dengan itu para raja di Jawa aktif di bidang budaya. KGPAA Paku Alam IV mempunyai perhatian besar dalam pengembangan seni tradisi khususnya tari. Banyak budaya Barat yang diserap dalam tarian yang digubah pada jamannya. Terdapat 5 nomor tarian lepas yang digubah pada masa pemerintahannya 3 diantaranya yaitu Beksan Floret, Sabel, dan Inum idenya berasal dari kebiasaan orang barat, yang kemudian digubah menjadi tarian dengan estetika Jawa.

Kata Kunci : Paku Alaman, Seni Tari. 


\section{A. PENDAHULUAN}

Seni termasuk di dalamnya seni tari merupakan bagian dari kebudayaan yang tidak dapat lepas dari kehidupan manusia. Dalam perjalanannya kebudayaan selalu bersifat dinamis, dan dari waktukewaktu selalu mengalami perubahan. Hal ini terjadi terutama karena adanya pengaruh budaya lain, sebagai dampak dari interaksi antar kelompok manusia pendukung budaya yang berbeda, persinggungan budaya ini menimbulkan rasa hormat pada budaya lain, dan terjadilah penyerapan hal-hal yang dianggap baik. Bagian dari budaya lain yang dianggap baik itu kemudian diadaptasi masuk dalam budaya masingmasing kelompok, sehingga secara keseluruhan budaya mengalami perubahan.

Seni tari tradisi yang hidup di istana sebagai bagian dari kebudayaan menunjukan nilai-nilai estetis budaya yang menaunginya. Konsep keindahan satu budaya dengan budaya yang lain tentu berbeda, hal ini berdampak pada masyarakat pendukung budaya yang seringkali tidak dapat menikmati keindahan yang terkandung dari sebuah produk budaya lain yang disebut seni. ${ }^{44}$ Pemahaman akan keindahan seni akan tumbuh pada seseorang, apabila ia memahami budaya yang melahirkan karya seni itu. Pemahaman pada budaya lain akan berdampak selain dapat menikmati keindahan produk budaya, juga akan mendorong munculnya penghargaan pada budaya lain. Kemampuan untuk memahami dan menghargai budaya lain diluar budayanya sendiri pada akhirnya menumbuhkan keinginan untuk mengadopsi hal-hal yang dianggap baik. Bagian budaya yang diadopsi, tentu disesuaikan dengan budayanya sendiri, dengan demikian terjadi proses adaptasi budaya.

Paku Alam IV, adalah Adipati di Puro Pakualaman yang bertahta antara tahun 1864 hingga 1878,55 sebagai raja di Puro Pakualaman ia adalah pecinta sekaligus seorang maesenas dan pengembang seni tradisi, khususnya seni tari. Di bawah pemerintahannya seni tari di puro Pakulaman berkembang pesat, banyak tari-tarian baru diciptakan. Jenis tari baru yang diciptakan, kemudian menjadi tari-tarian khas yang hanya ada di Puro Pakualaman. Dari bentuknya secara keseluruhan jelas bahwa tarian tersebut merupakan tari jawa dari tradisi istana, namun secara visual terdapat perbedaan jika dibanding dengan tari jawa lainnya.

Penelitian ini dimaksudkan mengkaji perkembangan tari-tarian di Puro Pakualaman, hinga terdapat tari-tarian yang unik dan hanya ada di Puro Pakualaman. Selain perkembangan, kekhasan tari-tarian di Puro Pakulaman menarik untuk dikaji, diketahui hal-hal apa sajakah

${ }^{54}$ Umar Kayam, Seni, Tradisi, Masyarakat, (Jakarta: Sinar Harapan, 1981), hlm. 23.

${ }^{55}$ Saktimulya, Sudibyo, Sumardiyanto, Warnasari Sistem Budaya Kadipaten Pakualaman Yogyakarta, (Jakarta : Trah Pakualaman Hudyana, 2012), hlm. 86 
yang membedakan tari-tarian yasan Paku Alam IV dengan tari-tarian jawa lainnya.

\section{B. BERDIRINYA PURA PAKU ALAMAN}

\section{Situasi Politik}

Memasuki Abad XIX terjadi perubahan besar di Jawa, sebagai akibat dari situasi Belanda yang bertubi-tubi menghadapi masalah keuangan akibat harus berperang baik melawan Inggris di quarter 4 Abad XVIII, Sementara VOC di Hindia Belanda hampir bangkrut dan perang itu berdampak pada VOC yang semakin terpisah dari induknya. Penyelidikan pemerintah Belanda terhadap VOC menghasilkan betapa buruknya kondisi VOC akibat salah urus, dan pejabatnya melakukan korupsi. Serangan Prancis ke Belanda pada tahun 1794 berhasil membentuk pemerintahan boneka, dan menempatkan Louis Napoleon (adik Napoleon Bonaparte), 1796 Hereen VII dibubarkan dan diganti dengan sebuah komite baru, dan terhitung 1 Januari 1800 VOC dibubarkan, asetnya kemudian dikuasai pemerintah Belanda. Akan tetapi perubahan itu tidak begitu berpengaruh pada rakyat di Hindia Belanda, mengingat pejabatnya masih sama dan mereka masih menerapkan cara-cara lama. Pemerintah Belanda di bawah Louis Napoleon, mengutus Marsekal Herman Willem Daendels untuk menjadi Gubernur Jenderal di Batavia pada tahun 1808. Hal ini dimaksudkan untuk memperkuat pertahanan Hindia Belanda, terutama Jawa dari serangan Inggris. 56

Daendels adalah seorang pejabat yang berpandangan anti feodalisme, sehingga ia tidak memandang para pejabat pribumi sebagai penguasa, tetapi lebih dianggap sebagai pegawai administrasi pemerintah kolonial. Di samping itu para raja bukan dipandang sebagai sekutu, tetapi dianggap taklukan. Oleh karenanya ia menuntut dalam tata upacara (protocol) kraton residen harus sejajar dengan raja, karena ia adalah minister. Menanggapi hal ini raja Surakarta Paku Buwana IV menyatakan menerima dan menyambut baik ide itu, tetapi berbeda dengan Hamengku Buwana II yang samasekali menolak. Sikap keras Hamengku Buwana II ini menjadi awal dari konflik berkepanjangan, yang pada akhirnya akan memicu pecahnya perang Jawa.

Persoalan yang dihadapi Daendels dalam mempersiapkan diri atas serangan dari Inggris adalah minimnya personel militer Belanda, sehingga ia harus mengandalkan 4.000 orang prajurit yang berasal dari

${ }^{56}$ Sartono Kartodirdjo, Pengantar Sejarah Indonesia Baru : 15001900 Dari Emporium Sampai Imperium, (Jakarta : Gramedia, 1987), hlm. 291. 
orang Jawa, yang kemudian ditingkatkan jumlahnya menjadi 18.000 orang. Walaupun sebagian besar dari prajurit kolonial ini bukan orang yang memegang teguh disiplin militer, tetapi dengan jumlah itu kekuatan Belanda harus mulai diperhitungkan, terlebih selain itu ia juga memperoleh dukungan dari raja Jawa (Mangkunegara II dan Paku Buwana IV). Mangkunegara II sesungguhnya punya rasa kebencian terhadap Belanda akibat penyitaan harta warisannya, namun dengan pertimbangan rasionalnya, ia lebih memilih bekerjasama dengan Belanda. Atas sikapnya itu Mangkunegara II diberi wewenang untuk membentuk Legiun Mangkunegara yang beranggotakan 1.150 orang dan dibiayai oleh Belanda.

Perubahan di Hindia Belanda mulai terasa ketika Willem V yang berhasil lolos dari serbuan Prancis dan mengungsi ke Inggris, mengeluarkan perintah kepada pejabat-pejabat di Hindia Belanda agar menyerahkan wilayahnya kepada orang-orang Inggris, agar tidak jatuh ke tangan Prancis. Inggris dengan kekuatan senjata yang lebih banyak dari Belanda berhasil merebut beberapa pos di yang semula dikuasai Belanda, dan memperoleh kekuasaan di beberapa wilayah seperti Padang dan Malaka (1795), juga Ambon (1796). Kehadiran Inggris ini tentu menyulitkan posisi pemerintah Hindia Belanda, terutama dengan blokade atas Batavia, yang sangat berpengaruh terhadap kegiatan ekspor Belanda khususnya kopi, yang pada puncaknya mengakibatkan merosotnya pendapatan Belanda. Pada tahun 1811 Daendels digantikan oleh Jan Willian Janssens, tetapi bersamaan dengan itu kekuatan Inggris sudah semakin mapan, dan dengan tiba-tiba pada 4 Agustus 1811 sebanyak 60 kapal Inggris muncul di Batavia. Jansen mundur ke Semarang, dan hingga akhirnya harus menyerahkan kekuasaan kepada Inggris.

\section{Konflik Internal}

Paska Palihan Nagari di bawah Sultan Hamengku Buwana I Yogyakarta tumbuh menjadi kerajaan yang kuat dan rakyatnya sejahtera. Bahkan ketika Sultan Hamengku Buwana I wafat (1792), dan kedudukannya digantikan oleh Sultan Hamengku Buwana II kerajaan ini masih sangat kuat. Menurut Ricklefs dalam Sejarah Indonesia Modern prajurit Sultan Hamengku Buwana II mencapai 1.765 orang, dan kekuatan prajurit ini masih mungkin dikembangkan dengan merekrut pasukan dari negeri-negeri taklukannya, hingga jumlahnya bisa mencapai 100.000 lebih.57 Keadaan ini sangat kontras dibanding jumlah serdadu Belanda di Yogyakarta yang hanya berjumlah 89 orang, itupun banyak diantaranya yang menderita berbagai penyakit. Namun demikian walaupun dipermukaan masalah pembagian wilayah telah selesai menjadi Kasunanan Surakarta, Kasultanan Yogyakarta dan Kadipaten

${ }^{57}$ M.C. Ricklefs, Sejarah Indonesia Modern, (Yogyakarta : Gadjah Mada University Press, 2005), hlm. 167-168. 
Mangkunegaran, ternyata di antara tiga kerajaan di Jawa Tengah ini masih selalu saling curiga, dan masing-masing mempunyai alasan untuk saling membenci. Ada kalanya Kadipaten Mangkunegaran bersekongkol dengan Kasultanan Yogyakarta untuk menentang Kasunanan Surakarta. Kadang terjadi pula persekongkolan dua kerajaan di Surakarta untuk menjatuhkan Yogyakarta. Dalam konflik internal tersebut Belanda selalu terlibat, baik itu melibatkan diri, atau karena diliatkan oleh para pihak yang bertentangan. Dalam keterlibatannya itu Belanda selalu saja menarik keuntungan, hingga akhirnya Jawa benar-benar terjajah.

Kasultanan Yogyakarta merupakan kerajaan yang paling merdeka dan unggul dalam kekuatan militer, namun keunggulan ini terancam oleh sikap Hamengku Buwana II yang sering tidak sejalan dengan kerabatnya terutama dengan Pangeran Natakusuma. Perselisihan itu berdampak pada stabilitas kerajaan, terlebih ketika ia mengganti para penasihat dengan orang-orang yang disukainya yang kadang kurang cakap. Dalam hal ini termasuk penggantian Patih Danureja I dengan Danureja II, yang dengan cepat menggalang persekutuan dengan sejumlah kerabat istana yang dekat dengan putera mahkota. Kerja paksa dan pajak yang diterapkan Sultan juga sangat membebani rakyatnya, terutama yang berada di wilayah mancanegara. Hubungannya dengan pejabat Belanda di Yogyakarta juga memburuk, akibat penghinaannya terhadap orangorang Belanda, yang kebetulan dalam keadaan lemah.

Kekuatan militer Kasutanan Yogyakarta ini tentu saja menimbulkan kekhawatiran pihak Kasunanan dan Mangkunegaran, yang kebetulan juga menyimpan rasa sakit hati pada Kasultanan Yogyakarta. Keduanya berusaha mengucilkan Kasultanan Yogyakarta, dan meminta Belanda untuk menghancurkannya. Bahkan keduanya menyatakan akan mendukung Belanda dengan pengerahan prajurit-prajuritnya. Dengan pernyataannya itu mereka berharap memperoleh keuntungan baik secara politis maupun finansial. Di sisi yang lain Paku Buwana IV juga melakukan komunikasi rahasia dengan Sultan Hamengku Buwana II, agar Sultan Berani menentang Belanda dan bahwa ia akan berada di belakang Sultan Hamengku Buwana II.

Daendels sebagai orang yang anti feodalisme, pada akhirnya mempunyai kesempatan untuk menyingkirkan Hamenku Buwana II, ketika Raden Rangga seorang kepala pemerintahan Sultan untuk daerah mancanegara yang secara diam-diam didukung oleh Sultan dan para pangeran, melakukan perlawanan terhadap Belanda. Perlawanan ini dengan mudah dipatahkan oleh Belanda, dan hal semakin meningkatkan ketegangan di dalam istana yang mendorong Sultan menyerahkan wewenang Patih Danureja II kepada Pangeran Natadiningrat putera Pangeran Natakusuma. Tindakan ini memicu Daendels untuk mengambil langkah keras terhadap Kasultanan Yogyakarta. Ia membawa pasukan yang cukup besar, dan memaksa Sultan turun dari tahta, dan menyerahkan kekuasaan kepada puteranya Hamengku Buwana III. Mengangkat dan mengembalikan kedudukan Patih Danurejo II. Pangeran Natakusuma dan Natadiningrat yang dianggap sebagai biang keladi 
perlawanan Raden Rangga ditangkap dan diasingkan ke Ceribon. Atas permintaan Hamengku Buwana III, maka Hamengku Buwana II tetap diijinkan tinggal di Yogyakarta. ${ }^{58}$

\section{Pangeran Mardika}

Moment serbuan Inggris hingga Janssens menyerah dimanfaatkan oleh Hamengku Buwana II untuk merebut kembali tahtanya, Hamengku Buwana III dikembalikan pada kedudukan semula sebagai putera mahkota. Raffles sebagai Gubernur Jenderal Jawa pada awalnya tidak bertindak apa-apa terhadap tindakan Hamengku Buwana II. Raffles dengan cerdik mempelajari sifat-sifat para penguasa Jawa, dan konstelasi politik yang berlangsung, sampai ia yakin benar pihak mana yang bisa dijadikan sekutu dan mana yang harus disingkirkannya. Selain Paku Buwana IV dan Mangkunegara II, Raffles juga memperhatikan Pangeran Natakusuma yang mempunyai dendam pribadi dengan Hamengku Buwana III. Kesimpulan diambil setelah Raffles mengalami sendiri perlakuan Hamengku Buwana II yang sulit diajak bekerjasama.

Raffles yang didukung mangkunegaran dan Pangeran Natakusuma berhasil menduduki istana Kasultanan Yogyakarta, dan merampoknya. Hamengku Buwana II ditangkap dan dibuang ke Penang. Kedudukan Sultan diberikan kepada Hamengku Buwana III, sementara atas jasanya Pangeran Natakusuma diangkat menjadi Pangeran Mardika bergelar Paku Alam, dan diberi daerah dengan 4.000 cacah yang dapat diwariskan (1813). Selain itu ia juga memperoleh wewenang untuk membentuk korps Paku Alam yang terdiri dari 50 orang kavaleri, dan 100 orang infantri. Pilihan Pangeran Natakusuma untuk mendukung Raffles, dan terlibat dalam serangan ke Kasultanan, selain alasan yang secara kasat mata dapat disimak, sesungguhnya punya tujuan lain, yaitu agar dapat turut mengendalikan serbuan itu sehingga istana tidak diratakan dengan tanah.

Peristiwa penyerbuan Istana oleh pasukan bangsa Barat, hanya sekali terjadi, tetapi telah cukup membuat para Pangeran merasa terhina, dan menjadi benih kebencian pada bangsa Barat. Hal ini disadari oleh pemerintah, oleh karenanya pemerintah kemudian mengubah politiknya dengan memberlakukan persamaan bagi Yogyakarta dan Surakarta, artinya apa yang dilakukan di Yogyakarta juga dilakukan di Surakarta. Hal itu dilakukan semata-mata untuk menjaga keseimbangan politik di kedua wilayah ini. Raffles sebagai orang yang anti feodalisme pada langkah-langkah berikutnya banyak mengamputasi pendapatan kelompok bangsawan, dengan cara menguasai daerah di luar Yogyakarta dan Surakarta, termasuk mengambil alih pengelolaan cukai lalu-lintas dan pasar.

58 Ibid., hlm. 172 
Pada tahun 1816 inggris harus mengembalikan daerah jajahan kepada Belanda, dan terpaksa harus meninggalkan Hindia Belanda, sebagai dampak dari penataan Eropa paska perang Napoleon. Di Hindia Belanda tindakan kaum penjajah ikut campur tangan terhadap urusan istana masih diteruskan, sehingga rasa tidak senang pada orang kulit putih yang telah ada sejak Daendels dan Raffles semakin meningkat. Gunung kebencian itu akhirnya meletus ketika perang Jawa dimulai. Banyak bangsawan mendukung Pangeran Diponegara, dalam kasus seperti ini secara fisik para raja tidak terlibat. Tapi di sisi lain memberi dukungan secara diam-diam. Perilaku seperti ini terjadi tidak hanya sekali bahkan sejak Giyanti, Penyerbuan Istana Yogyakarta, dan juga Perang Diponegara. Di ilhami ceritera tokoh pewayangan, seperti yang termuat dalam serat Tripama ${ }^{59}$ yaitu Sumantri, Kumbakarna, dan Karno yang menempatkan fisik dan batin pada dua sisi yang berbeda.

Perang Jawa yang berlangsung cukup lama itu ternyata menguras dana yang sangat besar, sehingga memaksa Belanda untuk melakukan pemulihan, dengan cara yang sangat menekan bangsa pribumi. Namun demikian tidak ada kekacauan yang ditimbulkan oleh permainan politik pihak kerajaan, dan jika ada perlawanan biasanya dilakukan oleh rakyat biasa dan dalam skala kecil, yang tentu mudah dikendalikan. Di Sisi lain para raja selalu mendapat pengawasan dan pembatasan wewenang. Dampak penguasaan bidang politik dan ekonomi oleh kaum penjajah, maka para raja mengalihkan perhatiannya di bidang kebudayaan. Sehubugan dengan itu wajar jika di era setelah perang di daerah vorstenlanden muncul pujangga-pujangga besar, ahli-ahli karawitan dan tari, ahli-ahli ukir, dan seni lainnya.

\section{SENI TARI PADA MASA KGPAA PAKU ALAM IV}

\section{Tari Di Puro Pakualaman}

Ketika Palihan Nagari terjadi, dan Mataram dibagi dua, yaitu Kasunanan Surakarta, dan Kasultanan Yogyakarta, ternyata tradisi tari gaya Mataraman turut diboyong ke Yogyakarta, sementara Surakarta menyatakan akan membuat gaya tari yang baru. ${ }^{60}$ Karenanya di jagat seni

${ }^{59}$ Serat Tripama adalah karya sastra yang memuat ajaran moral bagi para prajurit, yang mencontohkan tiga tokoh dalam pewayangan, yang masing-masing mempunyai pegangan sendiri dalam pengabdiannya.

${ }^{6060}$ Yuwono Sri Suwito, dalam ceramah "Perjanjian Giyanti" Puro

Pakualaman, 12 Feb. 2010, menyatakan bahwa: Dalam perjanjian yang ditandatangani di Giyanti antara Sultan Hamengkubuwana I, Sunan Paku Buwana III dan VOC, memang tidak disebut tentang tradisi dan symbol-simbol kebesaran raja. tetapi kenyataannya di balik VOC Sunan Paku Buwana III menyerahkan Kanjeng Kyai Kopek kepada Hamengku Buwana I, dan merelakan gaya seni tari di bawa ke Yogyakarta. 
tari, tari gaya Yogyakarta dikenal dengan sebutan tari klasik, sementara tari gaya Surakarta lebih disebut dengan gaya tari romantik. Seni

Tari Klasik Mataraman terlihat lebih anggun dibanding tari gaya Romantik, tetapi tari gaya Surakarta lebih halus dan geraknya mengalir tak putus. Tari dengan Gaya Klasik Mataraman inilah yang juga hidup dan berkembang di Puro Paku Alaman pada masa KGPAA PAku Alam I. Warisan budaya berupa tari di Puro Paku Alaman ini termuat dalam naskah-naskah scriptorium yang tersimpan di perpustakaan Puro Paku Alaman. Sehubungan dengan keberadaannya maka warisan budaya itu dapat diteliti, dan direkonstruksi kembali sehingga dapat dinikmati kembali oleh masyarakat luas.

Secara umum Seni tari sebagai sebagian warisan budaya tradisi di Puro Paku Alaman bersumber pada dua tradisi yaitu tradisi yang hidup di Kasultanan Yogyakarta, dan yang kedua tradisi yang hidup di Kasunanan Surakarta. Tradisi tari Kasultanan dengan gaya Mataramannya tumbuh dan berkembng di Puro Paku Alaman sejak KGPAA Paku Alam I bertahta hingga KGPAA Paku Alam VI.61 Tradisi tari Surakarta mulai tumbuh dan mengalami penyesuaian di Puro Paku Alaman sejak KGPAA Paku Alam VII memperistri putri Paku Buwana X, yakni BRA. Retno Puwasa dari Surakarta. Sejak itu tari dengan genre srimpi dan bedhaya Surakarta mewarnai Kadipaten Paku Alaman.

Pada masa KGPAA Paku Alam I, hingga KGPAA Paku Alam III tari yang berkembang, adalah tari tradisi yang hidup di Kasultanan. Tercatat tujuh repertoar tari yaitu Beksan Bancak Dhoyok, Beksan Inum kakung, Beksan Lawung, Beksan Paris, Beksan dhadhap, Srimpi Ela-Ela, dan Srimpi Gandrung Winangun. Nomor-nomor tari tersebut merupakan tari tradisi yang juga terdapat di Kasultanan Yogyakarta, sehingga dapat diduga bahwa tradisi tari di Puro Paku Alaman pada jaman PA I adalah kelanjutan tari tradisi di Kasultanan Yogyakarta.62 Namun demikian terdapat pula perubahan, seperti beksan Inum kakung di Kasultanan dikenal dengan nama Beksan Sekar Medura, atau Beksan Gendul.

\section{Beksan Floret dan Sabel}

Para penguasa di Puro PakuAlaman pada umumnya adalah para pemerhati dan pelestari tari, karena tari dalam tradisi Jawa dianggap pula sebagai pusaka, yang sangat pantas dijaga dan dihormati. Sehubungan dengan itu maka setiap Pangeran yang Jumeneng pasti menghasilkan karya tari seperti : PA II menghasilkan Bedhaya Semang, Beksan

${ }^{61}$ Naskah “Langen Wibawa” (LI.30), memuat lelangen beksan Puro Paku Alaman sejak PA I hingga PA V. Lihat juga Soedarisman Poerwokoesumo, Kadipaten Pakualaman. (Yogyakarta : Gadjah Mada University Press, 1985), hlm.40-65 Dipaparkan kepemimpinan di Puro Paku Alaman, hingga kesenian yang berkembang disana.

${ }^{62}$ Hermin Kusmayati, "Seni Tari" dalam Warnasari Sistem budaya Kadipaten Paku Alaman Yogyakarta, (Jakarta : Trah Hudyono, 2012), hlm., 78-81. 
Jemparing, Bedhaya Gandakusuma, Beksan Jebeng, dan Bandabaya. PA III, menghasilkan Beksan Lawung Ageng, Beksan lawung Alit, Beksan Jebeng. Demikian pula dengan yang lain menghasilkan karya baru atau melakukan pengembangan terhadap tari tradisi yang telah ada. Pada Masa Paku Alam IV, terjadi loncatan dalam pengembangan tari. Tercatat dalam serat Langen Wibawa, 5 nomor tarian yaitu Srimpi Nadheg, Beksan Floret, Beksan Sabel, Beksan Inum, dan Beksan Penthul Tembem. Dari 5 nomor tersebut Srimpi Nadheg belum terungkap bagaimana wujudnya, sementara yang lain telah dapat direkonstruksi. Dari 4 nomor yang telah terrekonstruksi jelas bahwa 3 nomor tari yaitu Beksan Floret, Sabel dan Inum dipengaruhi oleh budaya Barat. Dari 3 nomor yang dipengaruhi budaya Barat 2 nomor diantaranya adalah karya baru yaitu Beksan Floret danBeksan Sabel. Ternyata Beksan ini sesuai dengan namanya yaitu berangkat dari ide menstilisasi gerakan prajurit Belanda yang sedang berlatih memainkan pedang yang dikenal dengan olah raga anggar.

Dua nomor tari tersebut berpijak pada kaidah tari gaya Yogyakarta, tetapi kostum yang dipakai merupakan gubahan baru, dengan memakai atribut pakaian prajurit Belanda. Yang unik dari tari yang diberi judul beksan floret adalah dipakainya sepatu lengkap dengan kaos kakinya. Hal ini sangat kontras dengan tradisi tari Jawa pada umumnya yang selalu lepas alas kaki dalam menari. Perpaduan antara tradisi Barat dengan tradisi local menjadi sebuah bentuk sajian baru yang menarik, walau akar budaya masing-masing unsur masih dapat terbaca dengan jelas. Iringan Tarinyapun terdapat perpaduan antara music Barat yang diatonis dengan gamelan yang pentatonic. Semula memang rasanya ada yang aneh, tetapi ketika telah dimainkan bersama dan saling mengisi, iringanpun tampak serasi, sehingga penampilan dua nomor tari itu menjadi tontonan yang menarik.

\section{KESIMPULAN}

Tari sebagai bagian dari Budaya berkembang di Puro Paku Alaman, bahkan muncul karya-karya baru yang ide dasarnya berangkat dari budaya asing. Hal ini dimungkinkan karena istana pada jamannya tidak memungkinkan untuk aktif dibidang selain budaya. Aktivitas politik di dalam istana tentu akan mengakibatkan bencana, terutama karena adanya pengawasan dari pemerintah kolonial yang ketat. Tidak jauh berbeda situasinya, di bidang social ekonomi, Puro Pakualaman hanya mengelola sedikit sumber, berupa pungutan atas tanah di daerah yang kemudian disebut daerah Adikarto.

Munculnya tari baru berupa Beksan Floret dan Sabel pada Jaman PA IV, walaupun berpijak pada kaidah tari tradisi Kasultanan Yogyakarta, tetapi terdapat keberanian untuk mengolah unsur baru yang berangkat dari tradisi yang samasekali berbeda. Selain itu pemanfaatan 
atribut-atribut kebesaran serdadu Belanda yang melengkapi penampilan penari, merupakan hal-hal baru yang membedakan tari di Puro PakuAlaman ini dengan tari tradisi yang telah ada sebelumnya.

Terciptanya tarian baru itu tidak lepas dari penguasa yang bertahta, yang dalam hal ini Paku Alam IV, yang merupakan pecinta seni tari, tapi juga gandrung terhadap olah raga anggar yang sering dimainkan para serdadu Belanda yang berada di Puro paku Alaman sehubungan dengan adanya korps infantry dan Kavaleri. Berangkat dari hal-hal tersebut maka terciptalah Beksan Floret dan Beksan Sabel.

\section{Daftar Pustaka}

Naskah :

Langen Wibowo, (LI.30), Translitersi, Koleksi Perpustakaan Puro Paku Alaman.

\section{Buku :}

Brandon, James R., Theatre in Southeast Asia, Cambridge, Massachusetts: Harvard University Press, 1967

Endang Caturwati, Seni Dalam Dilema Industri, Yogyakarta: Yayasan Aksara Indonesia, 2004.

Hersapandi dan Begawan Ciptoning, Prambanan Menggugat, Yogyakarta: Yayasan Untuk Indonesia, 2000

Kuntowijoyo, Budaya dan Masyarakat, Yogyakarta: Tiara Wacana, 1999.

M. Agus Burhan, Jaringan Makna : Tradisi hingga Kontemporer, Yogyakarta : BP. ISI, 2006.

Ricklefs, M.C., Sejarah Indonesia Modern, Yogyakarta : Gadjah Mada University Press, 2005

Saktimulya, Sudibyo, B. Sumardiyanto, Warnasari Sistem Budaya Kadipaten Pakualaman Yogyakarta, Jakarta : Trah Pakualaman Hudyana, 2012.

Sartono Kartodirdjo, Pengantar Sejarah Indonesia Baru : 1500-1900 Dari Emporium Sampai Imperium, Jakarta : Gramedia, 1987

Soedarisman Poerwokoesumo, Kadipaten Pakualaman. Yogyakarta : Gadjah Mada University Press, 1985.

Soedarsono, The State Ritual Dance Drama in The Court of Yogyakarta, Yogyakarta: Gadjah Mada Univerity Press, 1984

Seni Pertunjukan Indonesia dan Pariwisata, Bandung: MSPI., 1999.

Seni Pertunjukan Indonesia di Era Globalisasi, Yogyakarta: Gadjahmada Unversity Press, 2002

Sumandyo Hadi. "Perkembangan Tari Tradisional : Usaha Pemeliharaan Kehidupan Budaya" dlm. Soedarso, ed. Perkembangan Kesenian Kita,Yogyakarta : BP ISI Yogyakarta,1991

Umar Kayam. Seni, Tradisi, Masyarakat. Jakarta : Sinar Harapan, 1981 